\title{
Is Verstehen Scientific Understanding?
}

\author{
Kareem Khalifa \\ Forthcoming in Philosophy of the Social Sciences
}

\begin{abstract}
Many have argued that the human sciences feature a unique form of understanding (Verstehen) that is absent from the natural sciences. However, in the last decade or so, epistemologists and philosophers of natural science have been proffering analyses of a kind of natural-scientific understanding. Using examples from educational psychology and anthropology, I argue that there are prima facie reasons to think these recent accounts of natural-scientific understanding impose necessary conditions on Verstehen. This suggests that any claim about Verstehen's distinctiveness faces hitherto-unappreciated burdens of proof.
\end{abstract}

Keywords: understanding, Verstehen, explanation, interpretation, naturalism

\section{Introduction}

In the philosophy of social science, understanding (Verstehen) involves the grasping of meaningful behavior, psychological states, practices, and cultural artifacts. Historically, hermeneuticists took Verstehen to distinguish the social from the natural sciences, while positivists demurred. While the arguments have matured over the years, the dialectical space has retained much of its $19^{\text {th }}$ century topology, with "interpretivists" (Stueber 2006) and "naturalists" (Roth 2003) taking over the respective roles of hermeneuticists and positivists. 
Traditionally, when philosophers of social science have debated about Verstehen, only interpretivists lay claim to a concept of understanding. However, current work in epistemology and the philosophy of natural science challenges this framework by offering more general concepts of understanding, intended to encompass both the human and natural sciences. These developments shift the terms of the debate. No longer is the question whether the human sciences alone aim at understanding. Rather, the question is whether and to what extent the human and natural sciences aim at the same kind of understanding.

Using the account of natural-scientific understanding from my book, Understanding, Explanation, and Scientific Knowledge (Khalifa 2017), I shall argue that the burden of proof hangs on interpretivists' shoulders, for understanding in the human sciences appears to have much in common with its natural-scientific cousin. I shall present my case as follows. Section 2 motivates infusing the debate between interpretivists and naturalists with the new literature on understanding. Section 3 presents my account of natural-scientific understanding, and extends it to a case of social-scientific understanding from educational psychology. Section 4 then extends it to an example from cultural anthropology. Given its application to these rather disparate examples, I suggest that we have some preliminary evidence in favor of naturalism. Section 5 then rehearses how interpretivists might reply to this challenge, and shows that they face substantial tasks going forward.

Before proceeding, I offer a caveat. In this paper, I shall only argue that all of the norms governing understanding in the natural sciences also apply to 
understanding in the human sciences. I will not broach the important question of whether the only norms governing understanding in the human sciences are those of the natural sciences. I hope to address this in future work. Furthermore, the reasons offered for naturalism are not intended to be conclusive. Rather, they are offered more in the spirit of reorienting the dialectical burdens concerning the distinctiveness of understanding in the human sciences.

\section{The Verstehen Wars}

Many have debated whether certain social sciences (hereafter, "the human sciences") feature a kind of understanding that is distinct from anything found in the natural sciences. For ease of reference, let's introduce some terminology. First, denote this allegedly distinctive form of understanding with the German "Verstehen." Typically, Verstehen is characterized as some kind of accurate simulation of another's mental states and processes, and human-scientific accounts-most notably intentional-action explanations-improve in proportion to the Verstehen they recruit, enable, or provide. Next, let's denote the kind of understanding common to all of the natural sciences with the phrase "scientific understanding." Furthermore, let "understanding" be the genus that includes both Verstehen and scientific understanding. Finally, for added flourish, let's call the debate as to whether Verstehen is distinct from scientific understanding "the Verstehen Wars." Those who claim that Verstehen is distinctive shall be called "interpretivists;" those who deny this, "naturalists." 
Earlier Verstehen Wars assumed that the only kind of understanding was Verstehen. Thus, interpretivists claimed that only the human sciences featured understanding, while naturalists claimed that understanding was no part of any science-human or otherwise. However, this may not be the most profitable way of carving up the landscape. Natural scientists have long claimed that understanding is one of their aims. For instance, Schrödinger $(1954,90)$ writes:

What are the peculiar, special traits of our scientific world-picture? About one of these fundamental features there can be no doubt. It is the hypothesis that the display of Nature can be understood.

Similarly and more recently, Nobel-winning astronomer Robert Kirshner $(1994,65)$ writes:

Understanding the history of matter and searching for its most interesting forms, such as galaxies, stars, planets and life, seems a suitable use for our intelligence.

Parallel developments in recent epistemology and philosophy of natural science also suggest that purveyors of Verstehen have no monopoly on the term "understanding." Here, the main questions are whether understanding is a species of knowledge, whether it traffics exclusively in truth, what kinds of cognitive abilities it requires, and even whether it requires explanation. ${ }^{1}$ Similarly, in the philosophy of the natural sciences, accounts of understanding have shed new light on idealization, modeling, realism, explanation, representation, and the aims of scientific inquiry.

${ }^{1}$ For a useful review, see Baumberger, Beisbart, and Brun (2016). 
Importantly, none of these positions makes any exception when human affairs are the objects of understanding. To be sure, some contributors to this burgeoning literature argue that understanding possesses a distinctive epistemic value that other epistemic standings (such as knowledge) lack (Kvanvig 2003, Pritchard 2010). However, even they make no special allowance for the human sciences. In other words, whatever distinctive epistemic value understanding has, it is understanding that applies just as much to the phenomena studied by physics as the phenomena studied by history or anthropology.

Against this backdrop, the older battle lines of the Verstehen Wars should be redrawn. No longer should we be asking, "Does a methodologically sound human science feature Verstehen?" Rather, we should be asking, "What, if anything, distinguishes Verstehen from scientific understanding?" On this new way of carving things up, interpretivists claim that something can fund this distinction; naturalists disagree. As mentioned above, I will offer only a partial and preliminary argument for naturalism, in that I will argue that Verstehen is a species of scientific understanding. This is partial because I will say very little about how Verstehen differs from other kinds of scientific understanding. It is provisional in that my arguments are based on just two examples of understanding in the social sciences, as well as some more general philosophical reflections. Additional examples could certainly falsify these claims.

These qualifications notwithstanding, I hope to shed some new light on the Verstehen Wars. First, if the arguments here are sound, then interpretivists will 
have a narrower but better-circumscribed problem space than before, for I will have shown that scientific understanding imposes necessary conditions on Verstehen. Thus, interpretivists will have to show that scientific understanding does not also impose sufficient conditions on Verstehen, or else the game is up. Second, my account of scientific understanding is formulated fairly precisely and lends itself to being evaluated by concrete examples from different sciences. In my estimate, earlier iterations of the Verstehen Wars have been sparse along both of these dimensions. Thus, I hope that my partial and provisional answer in favor of naturalism is nevertheless illuminating.

\section{The EKS Model}

I shall now present my account of understanding, which I call the ExplanationKnowledge-Science (EKS) Model. ${ }^{2}$ It has been applied, with varying degrees of detail, to numerous examples from physics (quantum mechanics, Galilean dynamics, statistical mechanics), ecology, and biomedical research. I now extend it to the social sciences. In this section, I examine how it fares with an example from educational psychology. In the next section, I look at ethnography.

I begin with a phenomenon that I suspect is familiar to many a reader. In the course of teaching, we frequently encounter students who are struggling with the material, yet, curiously, they seem the most reticent to come to office hours, seek tutoring, etc. What could explain this self-defeating behavior, and how might educators counteract it? In a widely cited study, Ryan, Gheen, and Midgley (1998)

${ }^{2}$ Please pronounce this as if it were the X-Model. 
studied 516 sixth-graders in 62 math classrooms to examine the effect of classroom's goal structure and social climate on this phenomenon of "help avoidance."

Using five-point scales, students were asked to assess the extent to which different statements were true of them. These scores were used as measures for the following four variables:

- Their proclivity to avoid seeking help.

- Their estimates of their ability to complete work or their "self-efficacy."

- Their perception of whether students in their class are largely rewarded for effort (a "task-based goal structure") or for being better than their peers (an “ability-based goal structure").

- Their perception of whether their teachers were providing social-emotional support in addition to academic support.

After running a hierarchical linear modeling (HLM) analysis on their data, Ryan et al. found that high self-efficacy and being male significantly increased help avoidance, while students' perceptions of the classroom as having a task-based (rather than ability-based) goal structure and an emotionally supportive teacher significantly decreased help avoidance. From this, they explain students' help avoidance as a confluence of these interacting factors. 
Let's assume that Ryan et al. have some understanding of why students sometimes avoid seeking help. ${ }^{3}$ How are we to unpack this? Enter my EKS Model. Its core ideas are threefold: 4

Minimal Understanding: Minimal understanding of why $p$ is having an approximately true belief in an explanation of $p$.

The NeXUs PRINCIPLE: Understanding of why $p$ improves in proportion to the amount of explanatory information about $p$ that is grasped, i.e. to the degree to which p's "explanatory nexus" which is grasped.

The SCIENTIFIC KNOWLEDGe PRINCIPLE: Understanding of why $p$ improves in proportion to the resemblance of this grasp to scientific knowledge of why $p$. The latter two claims highlight an oft-undertheorized point in the understanding literature: understanding admits of degrees. Thus, we can see any particular instance of understanding as requiring belief in one or more approximately true explanations of the same phenomenon, plus some further resemblance to scientific knowledge. Like other kinds of resemblance, what counts as similar enough is a matter of context.

\footnotetext{
${ }^{3}$ In this example and the next, I assume that the social scientists have succeeded in understanding the phenomena of interest. Should this assumption turn out to be false, then it suffices for my purposes if the social scientists sought understanding of these phenomena. In either case, the norms of understanding would remain the same; the only difference would be whether the social scientists lived up to those norms.

${ }^{4}$ Khalifa (2017) presents these ideas more precisely. I have opted for a breezier exposition here.
} 
This raises two key questions. First, what is an explanation? The EKS Model adopts a thin account of explanation, which holds that $q$ explains why $p$ if and only if:

(1) $p$ is (approximately) true;

(2) $q$ satisfies your favorite (but reasonable) ontological requirements;

(3) $q$ makes a difference to $p$; and

(4) $q$ satisfies the relevant local constraints.

Consider, for instance, that a lower sense of self-efficacy explains why some students are reluctant to seek help. The first condition is uncontroversial: if no students were reluctant to seek help, there would be nothing to explain. The second condition is designed to circumvent the scientific realism debate. If you're an antirealist, then presumably you will only require your explanans to be utile, empirically adequate, etc. If you're a realist, you'll demand greater fidelity to the world. In our example, different psychologists might well have differing stances toward the ontological status of students' sense of self-efficacy. Some may think it refers to a robust psychological motivation, others to a useful operational definition, etc. The EKS Model's second condition on explanation is designed to be accommodating on this front.

The third requirement on explanation echoes a widespread idea in the explanation literature, namely that explanations ought to tell us what would happen to the explanandum if the explanans were different (Woodward 2003). Given the statistical methods used, there is no doubt that this is in play here, for 
the claim (at root) is that students' sense of self-efficacy makes a statistically significant difference to their proclivity toward help avoidance. Finally, as a scientific pluralist, I'd like to leave room for a variety of different kinds of explanations. My fourth, local constraint does just this. In this particular case, Ryan et al. focus on some the causes of help avoidance that concern student perceptions.

The EKS Model's second key concept is scientific knowledge. I hold that scientific knowledge of why $p$ is achieved when one's belief in an explanation of $p$ is "safe" because of one's scientific explanatory evaluation (SEEing). A belief is safe if and only if it could not easily have been false given the way it was actually formed (Pritchard 2005). This entails that it is true, and provides useful way of unpacking how beliefs can be reliably formed. SEEing consists of three stages: (a) considering plausible potential explanations of a phenomenon, (b) comparing those explanations using the best available scientific methods and evidence, and (c) basing one's (typically doxastic) commitments about those explanations on those comparisons. Thus, the claim is that scientific knowledge of an explanation is achieved when one's explanatory commitments could not easily have been false given the way that one considered and compared that explanation to plausible alternatives of the same phenomenon.

Ryan et al. engage in SEEing. They consider not only the explanatory factors canvassed above (self-efficacy, gender, goal structure, and social-emotional support), but also teacher attitudes about their goal and support structure. They not only consider individual student perceptions, but also aggregate classroom perceptions of 
self-efficacy, goal structure, and social-emotional support. This latter point is what leads them to adopt HLM rather than standard ordinary least squares analyses, since it is better method for comparing individual- and group-level effects.

Moreover, in their comparisons, they found that some variables-such as teacher attitudes and perceptions_-make no difference to help avoidance, and also find interesting interactions between other variables such as self-efficacy and gender. Finally, they draw the appropriate inferences from these different comparisons: some variables are taken to be explanatory, while others are not. Moreover, Ryan et al.'s SEEing makes their beliefs safe. Statistical methodology is largely designed to make sure that the null hypothesis could not easily have been true (in which case, the alternative would have been false.) ${ }^{5}$

Thus, as a first run through a social-scientific example, the EKS Model does quite well. Educational psychologists appear to believe in an approximately true explanation of help avoidance, thus MINIMAL UNDERSTANDING is satisfied. Furthermore, in accord with ThE NeXUs PRINCIPLE, they do not rest content with a single explanation of help avoidance, but seek to grasp multiple explanations (involving self-efficacy, gender, and teachers' emotional supportiveness) and their interrelations. Finally, their grasp of these explanations involves safe consideration, comparison, and explanatory commitments, which are characteristic of scientific

5 There is much work to be done linking modal epistemology to statistical methodology. See Roush (2007), for example. 
explanatory evaluation (SEEing), just as The SCIENTIFIC KNOWLEDGE PRINCIPLE suggests.

\section{Ilongot Headhunting}

Admittedly, Ryan et al.'s is one of the "easier" social-scientific examples for an account of scientific understanding, such as my own, to cover. It uses statistics and a quasi-experimental design. Nevertheless, it is an intentional-action explanation that is readily accommodated by an account of scientific understanding. I'll now apply the EKS Model to an example that seems better-positioned to favor interpretivism —an example from cultural anthropology that has no statistics and that does not readily lend itself to anything resembling an experimental set-up. The EKS Model's success here should begin to give erstwhile interpretivists greater pause.

The Ilongot are a tribe indigenous to the east side of Luzon, the largest island in the Philippines. Most infamously, they are known to engage in headhunting. Given that this practice is regarded as so abhorrent and morally incomprehensible in many other cultures—especially the Western cultures in which most anthropologists are reared—Ilongot headhunting is puzzling. To fill this gap in our understanding, Renato Rosaldo (1980) stayed with the Ilongot on two separate occasions: from 1967-1969, and again in 1974. During these periods, he conducted multiple interviews and engaged in extensive ethnographic observation of the Ilongot in order to get a grip on their headhunting practices. 
The EKS Model readily captures the understanding that Rosaldo gained. Begin with Minimal UnDERSTANDING. Rosaldo explains several aspects of Ilongot headhunting, though the most fundamental is why Ilongot men take heads. Rosaldo explains this phenomenon as follows: headhunting is the culmination of several rites of passage that young Ilongot men undergo in their transition to full-blown adulthood. Those who have not yet taken a head are called "novices" (siap). Novices tend to be envious of those who have taken heads and have thereby "arrived." The latter are marked by curved red hornbill earrings, which garner the admiration of young women, and entitle their wearers to retort to taunts from older men. By contrast, married novices are taunted, typically with jokes about wanting to behead their wives, and are not supposed to answer back. Thus, Ilongot men take heads because it is a rite of passage. Moreover, Rosaldo $(1980,140)$ describes headhunting's symbolic meaning:

To take a head is, in Ilongot terms, not to capture a trophy, but to 'throw away' a body part, which by a principle of sympathetic magic represents the cathartic throwing away of certain burdens of life - the grudge an insult has created, or the grief over death in the family, or the increasing 'weight' of remaining a novice when one's peers have left that status.

Turn now to the four conditions from my thin account of explanation. The first condition requires the explanandum to be approximately true, and it is: many Ilongot men take heads. ${ }^{6}$

${ }^{6}$ Linguistically speaking, this statement is probably best understood as a generic. 
Next, consider the explanans. All indications are that Rosaldo takes headhunting's status as a rite of passage and a symbolic unburdening to be genuine motivations of why Ilongot men engage in this practice. In other words, this explanans appears to be more or less true, which thereby satisfies a reasonable ontological commitment.

Furthermore, while he does not explicitly speak of difference-making, it would be natural to interpret him as committed to the counterfactual claim that, ceteris paribus, if taking a head were not a rite of passage for Ilongot youths, then, in general, Ilongot men would not take heads. Furthermore, it is clear that he is seeking cultural causes of Ilongot headhunting, which can be regarded as a local constraint. Additionally, he clearly disavows deterministic causation as a local constraint (Rosaldo 1980, 152-153). Consequently, all of the requirements of my thin account of explanation are satisfied. It is also natural to interpret his writing as assertoric. Hence, he appears to believe this explanation. Thus, according to the EKS Model, Rosaldo has minimal understanding of why Ilongot men take heads.

Turn now to the THE NEXUs PRINCIPLE, which states that understanding improves in proportion to the amount of explanatory information grasped. Not only does Rosaldo identify the cultural factors that contribute to Ilongot headhunting, but he also examines historical-political factors of headhunting, such as feuds between different Ilongot groups (betran) (Rosaldo 1980, 61-79) and psychological factors that drove individual Ilongot men, such as the ever-volatile Luku, to take heads at particular times (Rosaldo 1980, 164-165). These explanations also satisfy 
the requirements of my thin account of explanation, but, more importantly, having all three kinds of explanation—cultural, historical-political, and psychological— improves our understanding of Ilongot headhunting, as the THE NEXUs PRINCIPLE states. Thus, we see yet another way in which the EKS Model readily accounts for Rosaldo's understanding of Ilongot headhunting.

The EKS Model's third and final feature is THE SCIENTIFIC KNOWLEDGE PRINCIPLE, which holds that understanding improves to the degree that one's grasp of explanatory information resembles scientific knowledge. Recall that scientific knowledge of an explanation, in turn, was defined as a belief that is safe because of scientific explanatory evaluation (SEEing). Rosaldo exhibits all three of SEEing's aforementioned stages. First, he considers several plausible potential explanations of Ilongot headhunting. In addition to the cultural, historical-political, and psychological factors just discussed, Rosaldo also considers other explanations, such as that historically invariant social structures explain Ilongot headhunting (pp. 2627); that the Ilongot testimony he acquired was mendacious (pp. 109-134); and that Ilongot men are obligated to take heads (pp. 141-142).

The second and third stages of SEEing involves comparing the explanations considered and committing oneself to various explanatory claims on the basis of those comparisons. The last three candidate explanations were ultimately rejected on the respective grounds that:

- Ilongot headhunting waxed and waned at different periods from 1883-1974, and hence could not be the result of an invariant social structure. 
- Careful investigation of Ilongot testimonial norms across a wide variety of domains reveals them to be strongly error-averse: one rarely testifies to something that one has not witnessed firsthand. Furthermore, claims about headhunting were robust across different testimonial sources.

- The presence of married novices, plus evidence that the idea that Ilongot were obligated to take heads sprung from gossip and Christian propaganda. Comparisons need not always involve explanatory competition. Often, comparisons reveal interactions or complementarities between explanations. ${ }^{7}$ Rosaldo does precisely this with the cultural, historical-political, and psychological explanations that he accepted. For instance, intergenerational feuds between different betran leads to a host of psychological burdens. Members of one betran may harm members of another, such that the latter's sons are both saddened and insulted. Headhunting is a way for the sons to unburden themselves of these emotions.

However, whereas the norm appears to be that the taking of nearly any head has this cathartic effect, the aforementioned Luku, a member of the Rumyad betran, was somewhat unique in passing up the opportunity to take the head of an outsider, and insisting instead on taking the head of a member from the rival Butag betran. While this was not consonant with Ilongot norms concerning headhunting, Luku felt compelled to do so because a member of the Butag had threatened to kill his father fifteen years earlier in 1935 . When Luku finally took a Butag head in 1950

\footnotetext{
${ }^{7}$ Recall the passing mention of the interaction between gender and self-efficacy in the educational psychology example.
} 
(and at the same time that elder Rumyads were negotiating a truce with the Butag), this reignited the feud between the Rumyad and Butag. Thus, there is a rich tapestry of relations between Rosaldo's cultural, historical- political, and psychological explanations.

Importantly, the EKS Model urges comparisons between explanations to be done on the basis of the best available methods and evidence. Not only does Rosaldo use standard ethnographic methods, such as in-depth interviews of multiple Ilongot members, but he very explicitly discusses how ethnographers can do historical work and apply it in societies, like the Ilongot, who do not have written records of their past. To that end, he took special measures to overcome methodological difficulties that other anthropologists have raised with respect to inferring historical claims from interviews (Rosaldo 1980, 14-28). He also provides a detailed discussion of his method of "cohort analysis" (Rosaldo 1980, 110-120) in which groups of similarlyaged Ilongot were studied longitudinally, in order to transform "the composite biography into a collection of individual biographies in their historical, cultural, and social structural contexts" (Rosaldo 1980, 110). Cohort analysis was not used widely in ethnography, though it was a standard method in the adjacent fields of demography, sociology, and social history.

Thus, it appears that Rosaldo's inquiry includes many features of THE SCIENTIFIC KNOWLEDGE PRINCIPLE. Insofar as anything is absent, it is that he makes no explicit references to anything resembling safety, i.e. that his explanations could not easily have been false. However, as I argue elsewhere 
(Khalifa 2017, 48-50, 194-207), unsafe methods and unsafe evidence seem ill-suited to scientific practice. Very roughly, it would license rather reckless explanatory reasoning. Additionally, unsafe explanatory commitments would render the value of understanding somewhat mysterious: why would anyone seek to have explanations that easily could have been false?

In summary, just as we saw all three features of the EKS Model in full display with our example of educational psychology, we see the same in Rosaldo's understanding of Ilongot headhunting. When coupled with its earlier applications to the natural sciences, naturalists have license for optimism. Understanding in the human sciences does not appear to be different in kind than understanding in the natural sciences.

\section{Verstehen as Scientific Understanding}

Of course, these are only two examples. Ideally, detailed case studies would be used to settle my recasting of the Verstehen Wars, but one can only do so much in a single paper! Nevertheless, I now examine some of the conceptual challenges that interpretivists face in resisting my claim that Verstehen is a species of scientific understanding. 8

More precisely, if Verstehen were not a species of scientific understanding, then it would have to contravene Minimal Understanding, The NeXus PRINCIPLE, or The SCIENTIFIC KNOWLEDGE PRINCIPLE. Furthermore, if interpretivists succeeded

${ }^{8}$ Recall that this paper only argues that if one has Verstehen, then one has understanding in the manner prescribed by the EKS Model. For the purposes of this paper, I remain agnostic as to whether the converse is true. 
in establishing that one of the EKS Model's three features is absent from Verstehen, they would also have to show that this same feature is present in understanding found throughout the natural sciences. Otherwise, interpretivists will only have shown that the EKS Model imposes unnecessary constraints on both Verstehen and scientific understanding, which would not get interpretivists their desired bifurcation. Call this the Distinction Test.

In what follows, Sections 5.1 through 5.3 argues that interpretivists' prospects of forgoing the EKS Model's strictures while passing the Distinction Test appear bleak. Section 5.4 concludes this section by arguing that the EKS Model imposes stronger necessary conditions on scientific understanding than other extant proposals, and thereby makes it easier for interpretivists to pass the Distinction Test than other proposals in the new literature on understanding. Hence, interpretivists face far steeper dialectical burdens in arguing for the claim that Verstehen is not a kind of scientific understanding than has been countenanced.

\subsection{Verstehen without Minimal Understanding?}

Recall my account of Minimal Understanding:

Minimal understanding of why $p$ is having an approximately true belief in an explanation of $p$.

As I see it, interpretivists can deny this in one of two ways. First, they can deny that Verstehen requires approximate truth. Second, they can deny that Verstehen requires explanation. 
Denying that Verstehen traffics in approximate truth seems curious. After all, the goal of Verstehen appears to be an accurate depiction of another person's mental life. Furthermore, the hedge-that the explanation be approximately true-is meant to dispel utopian demands for top-shelf fidelity to every detail of another's inner workings. So, the basic picture is that one must get something about another's perspective more or less right in order to understand. Interpretivists would have to find social-scientific examples that forgo this basic requirement in order to show that Verstehen need not be approximately true. This is no small feat.

Our examples certainly provide no indication that this is the case. Suppose, for instance, that self-efficacy, gender, and student perceptions classroom goal structure and of their teachers' emotional supportiveness did not explain patterns of help avoidance, or that headhunting's status as a rite of passage did not explain its prevalence among Ilongot men. In such cases, one might reasonably worry that our inquirers have misunderstood help avoidance or Ilongot headhunting. Moreover, this does not appear to be peculiar to these sorts of examples.

A more promising way of challenging Verstehen's veridicality would be to embed it in a kind of antirealism. Perhaps competent interpreters need not believe that propositional attitudes and mental representations exist, but they nevertheless use them for predicting and explaining others' actions. However, it is hard to see how this will pass the Distinction Test. After all, some have suggested precisely the same stance be adopted toward theoretical entities in the natural sciences (van Fraassen 1980). Indeed, as we have seen, my thin account of explanation is 
amenable to explanation having more relaxed ontological requirements than scientific realists require. ${ }^{9}$

If interpretivists cannot overcome these obstacles to denying MINIMAL UNDERSTANDING'S requirement of approximate truth, then perhaps they would be better served to deny that Verstehen requires explanation. This claim, of course, has a much longer history in the Verstehen Wars, for Verstehen was frequently contrasted with Erklären, i.e., explanation. However, such arguments have been repeatedly thwarted on the grounds that they caricature explanations in the natural sciences. For instance, while Erklären-qua-interpretivist-bogeyman has, at various points, required laws and causation, it's highly doubtful that the life sciences traffic in the nomological (Woodward 2001, Mitchell 1997) and there has been a profusion of philosophical discussions about noncausal explanations throughout the natural sciences (Reutlinger and Saatsi 2018).

The EKS Model is chastened by these and other developments, and thus imposes more modest requirements on explanation than interpretivists have considered. Indeed, its most distinctive requirement—-that the explanans make a difference to the explanandum-is one that I have, in subsequent work, questioned as a universal constraint on all explanations (Khalifa, Doble, and Millson forthcoming). All of this makes interpretivist attempts to pass the Distinction Test unpromising.

\footnotetext{
${ }^{9}$ Khalifa (2017, Ch. 6) discusses scientific understanding's relationship to truth, including its antirealist variants, in greater detail.
} 
Let me consider two more avenues for divorcing Verstehen from explanation. First, recall that on my account of explanation, the explanandum must be approximately true. Our examples seem to accord with this basic idea: certain students avoid seeking help and the Ilongot take heads. However, one might argue that Verstehen requires a special kind of interpretation of the phenomenon to be understood.

Unfortunately for interpretivists, it's unclear how this challenges MINIMAL UNDERSTANDING. Such interpretations would have to issue profoundly false descriptions of the phenomenon and obviate the need for explanation. To my knowledge, this argument has not been made. Moreover, philosophers of natural science working on measurement have recently availed themselves to hermeneutical resources (van Fraassen 2008, Cupples ms), which suggests that this proposal will fail the Distinction Test.

Second, interpretivists might profit by borrowing a concept from recent work on understanding. Thus far, we have focused on understanding why, or explanatory understanding. This is frequently contrasted with objectual understanding (Elgin 2017, Kvanvig 2003, Carter and Gordon 2014, Baumberger and Brun 2017, Dellsén , Kelp 2015). The clearest difference between explanatory and objectual understanding occurs at the level of grammar. Paradigmatic expressions of explanatory understanding have embedded explanation-seeking questions as their complements, e.g. Rosaldo understands why the Ilongot take heads. In contrast, 
objectual understanding takes noun phrases as its complement, e.g. Rosaldo understands Ilongot headhunting.

Objectual understanding is generally thought to be achievable without explanation. For instance, simply being able to situate a phenomenon in a broader inferential framework might garner some degree of objectual understanding. ${ }^{10}$ Moreover, thinking of Verstehen as a kind of objectual understanding is highly suggestive, for interpreters seem to seek understanding of people and not simply understanding of why those people do and think various things.

However, such a strategy is not without its difficulties. Those who have defended objectual understanding make no special allowance for the human sciences, so interpretivists run the risk of flunking the Distinction Test. Furthermore, arguments for a kind of objectual understanding that swings completely free of explanatory understanding are not without their liabilities. In particular, I have argued that nothing of philosophical importance is lost if all instances of objectual understanding are treated as one or more instances of:

(a) explanatory understanding, or

(b) being on the right track to having explanatory understanding (Khalifa 2017, Ch. 4).

\footnotetext{
${ }^{10}$ Since I'm focused on challenges to the necessity of the EKS Model, I bracket claims about whether objectual understanding sometimes requires more than explanatory understanding. See Khalifa (2017, Ch. 4) for my full treatment of objectual understanding.
} 
Consider the claim, "Rosaldo understands Ilongot headhunting." My view correctly predicts that Rosaldo has many approximately true beliefs that correctly answer different why-questions about Ilongot headhunting. For instance, he can explain why the Ilongot take heads, why Ilongot headhunting escalated from 1950-1952, etc.

However, in other regards, much of his ethnography appears "merely descriptive." For example, he discusses Ilongots' language for remembering past events. This is where condition (b) enters the scene: despite not providing an explanation, and thereby not providing understanding why, this ethnographic information nevertheless plays an explanatory role that puts one on the right track to further explanatory understanding of some facet of Ilongot headhunting.

Specifically, if this kind of "proto-understanding" were not countenanced, then it becomes increasingly difficult to account for why some descriptions about a subject do not appear to enhance our understanding. For instance, why is Rosaldo's description of Ilongot ways of describing the past illuminating of their headhunting practice while the true statement, "Either Ilongot take heads or unicorns exist," is not? A plausible answer is that only the former can play an explanatory role, and thus puts inquirers on the right track to explanatory understanding. Specifically, because Rosaldo is using Ilongot testimony to determine why different periods of their history had varying levels of headhunting, it is important that he have an accurate way of inferring historical claims from their testimony. In this way, claims 
about their descriptions of the past play an explanatory role as evidence that can be used for confirming explanations about historical patterns of headhunting.

Thus, we have seen that interpretivists face formidable challenges in denying the EKS Model's account of minimal understanding, which requires approximately true beliefs in explanations. To deny that Verstehen must be approximately true seems to either to contravene an obvious aim of the human sciences (getting another person's mental life right) or to collapse interpretivism into a non-distinct kind of scientific antirealism. To deny that Verstehen traffics in explanation fails to respect the diversity of explanations in the natural sciences or requires unpacking the rather mercurial concept of objectual understanding. In principle, these challenges are surmountable, but they are far from trivial, either.

\subsection{Can Verstehen Bypass the Explanatory Nexus?}

If Verstehen and scientific understanding are both committed to MINIMAL UNDERSTANDING, then, in the present context, interpretivists will have to argue that Verstehen does not improve in accordance with the EKS Model's two remaining features. Recall that the EKS Model's first norm for improving understanding is THE NEXUs PRINCIPLE:

Understanding of why $p$ improves in proportion to the amount explanatory information about $p$ that is grasped.

We can see the amount of explanatory information as a function of three things:

- The number of correct explanations and inter-explanatory relations grasped 
- The quality/importance of the explanations and inter-explanatory relations grasped

- The level of detail of the explanations and inter-explanatory relations grasped (Khalifa 2017, 10)

Thus, interpretivists should find examples in which social scientists are confronted with two or more accounts of the same phenomenon, and opt for one that is strictly dominated along these three dimensions. Ideally, the social scientists would provide compelling methodological reasons for their choice.

Having laid out the burden of proof, I must profess ignorance as to whether social-scientific practice will favor interpretivists or naturalists. However, let me offer two motivations for tethering Verstehen to ThE NEXUs PRInCIPLE. First, The NEXUs PRINCIPLE easily piggybacks on the preceding arguments for MINIMAL UNDERSTANDING. The basic idea is this: because MinIMAL UnDERSTANDING entails that one gets some understanding by getting a little bit of explanatory information, it's natural to think that one gets more understanding with more explanatory information-but this is precisely what THE NEXUS PRINCIPLE counsels.

Insofar as there may be room for claiming that Verstehen does not improve in proportion to explanatory information, it is that certain kinds of explanatory information do not seem to enhance Verstehen. For instance, suppose that Rosaldo's ethnographic work could be integrated with findings in cognitive neuroscience. One might argue that this enhances our scientific understanding, but not our Verstehen, of Ilongot headhunting. However, it is hard to see how this line of argument will 
pass the Distinction Test. For instance, just as our hypothetical anthropologists can safely ignore neuroscientific factors that affect Ilongot headhunting, physicists working in classical regimes can often safely ignore quantum-mechanical and relativistic explanatory factors. To put this another way, this just seems to conflate the fact that inquirers of all persuasions sometimes favor the quality or relevance of explanatory information over its sheer quantity.

To summarize, interpretivists could bolster their case by showing that interpreters sometimes leave explanatory information on the table in favor of something more Verstehen-esque. The jury is still out on that. However, even if such an example is found, it will have to dissolve the tight link between MINIMAL Understanding and The Nexus PRINCIPLE (perhaps by undercutting motivations for the former), and will have to show that forgoing THE NEXUS PRINCIPLE is not an instance of the everyday scientific practice of focusing on some explanatory factors while downplaying others.

\subsection{Does Verstehen Resemble Scientific Knowledge?}

\section{Recall The ScIENTIFIC KNOWLEDGe PRINCIPLE:}

Understanding of why $p$ improves in proportion to the resemblance of this grasp to scientific knowledge of why $p$.

Furthermore, scientific knowledge of an explanation was characterized as a safe belief in an explanation that is because of SEEing. We can see resemblance to this knowledge as having several dimensions: 
- The number of plausible potential explanations that the agent has considered

- The number of considered explanations that the agent has compared using scientifically acceptable methods and evidence

- The scientific status of the methods and evidence that the agent used to compare the explanations

- The safety of the agent's beliefs about explanations

- The accuracy of the agent's beliefs about explanations

- The variety of ways that the agent can use explanatory information so as to achieve different scientific goals (Khalifa 2017, 13-14)

As with The NeXus PRINCIPLE, if interpretivists wish to challenge THE SCIENTIFIC KNOWLEDGE PRINCIPLE as a norm governing Verstehen, they should find examples in which social scientists are confronted with two or more accounts of the same phenomenon, and opt for one that is strictly dominated along these six dimensions. Ideally, the social scientists would provide compelling methodological reasons for their choice.

Having presented this burden of proof, I must once again profess ignorance as to whether social-scientific practice will favor interpretivists or naturalists. However, as before, I think that there are reasons to link Verstehen to THE SCIENTIFIC KNOWLEDGE PRINCIPLE. First, this principle helps to mitigate certain kinds of underdetermination. Here, I have no fancy, philosophical underdetermination in mind, but the workaday underdetermination that scientists encounter when they puzzle over whether something else is actually explaining the 
phenomena of interest, agonize over potential confounds, etc. This kind of underdetermination appears especially prevalent in sciences where Verstehen is most at home. After all, these human sciences rarely feature controlled or replicable experimentation. Thus, if interpretivists deny that Verstehen is subject to THE SCIENTIFIC KNOWLEDGE PRINCIPLE, they face a further burden of proof. Either they must show that the human sciences rule out just-so stories through some other structure than SEEing, or else they must show that just-so stories are on a methodological par with explanations that accurately depict the structure of human action. These additional burdens of proof are nontrivial.

Second, the Distinction Test looms large once again. The EKS Model grants that different sciences will have different methods and different evidence for comparing explanations. For instance, what do particle colliders and bacterial cultures have in common? Why treat different kinds of statistical tests, much less non-statistical tests, as of a single kind? In short, the EKS Model is compatible with science exhibiting a substantial "disunity of method" (Wylie 1999). Hence, interpretivists must show that there is something common to all natural-scientific methods of explanatory comparison that is absent in the human sciences.

\subsection{The Distinction Test: Further Reflections}

I have noted that if Verstehen is discordant with the EKS Model, this does not automatically vindicate interpretivism. In particular, if Verstehen and some natural sciences diverge from the EKS Model in the same way, then the proper response is 
not to embrace interpretivism, but to reject the EKS Model. That is the crux of the Distinction Test. I conclude my discussion by pointing out that the EKS Model is among the more demanding accounts of scientific understanding. ${ }^{11}$ Hence, interpretivists' prospects of passing the Distinction Test are not altogether bright.

Roughly, we can see two sorts of constraints on natural-scientific understanding in the literature: ability-based and coherentist. I will show that the EKS Model provides the most demanding versions of these constraints. I stress that what matters for the purposes at hand is demandingness, not plausibility (though of course I have my biases on this latter issue as well!)

Consider those who hold that understanding largely consists of fitting a phenomenon into a coherent system of beliefs (Elgin 2017, Carter and Gordon 2014, Riggs 2009, Kvanvig 2003). It is unsurprising that this kind of understanding is common to the natural and social sciences. With rare exception, scientists aim to fit their explanation with their other theoretical and empirical commitments. Unsurprisingly, then, few coherence-based constraints on understanding are even pitched as dividing lines between natural- and social-scientific understanding. Indeed, Elgin (2017) provides the most developed coherentist-based account and highlights several commonalities between scientific, humanistic, and artistic understanding.

${ }^{11}$ Space being limited, these comparisons will have to be somewhat cursory. See references for closer comparisons that I've made elsewhere. 
More directly, the EKS Model also countenances typical coherence-making relationships, e.g. logical, probabilistic, and explanatory relationships between propositions. However, these relationships only provide understanding insofar as they figure in SEEing. No other coherence-based constraints on understanding require this, and instead are fairly underspecified about the cognitive processes that yielded these coherence-making relationships. Hence, the EKS Model is more demanding than these coherentist approaches. ${ }^{12}$

Turn now to ability-based constraints, which claim that understanding is only achieved when certain abilities are exercised. They are more varied than coherentist approaches, and so require more extensive discussion. The EKS Model's trademark abilities are those characterizing SEEing: consideration, comparison, and the inferences required to go from explanatory comparisons to explanatory commitments. Additionally, one must have the requisite abilities to wield the EXPLAINS concept, i.e. one must be able to explain.

Thus, views which only require understanders to be able to explain (Greco 2013, Pritchard 2014) will be less demanding than the EKS Model, since they will not have any rider about SEEing. Some views attempt to specify this explanatory ability in greater detail, typically by adding that understanders must be able to engage in counterfactual reasoning of some sort (Hills 2015, Grimm 2014). However, this is also required by the EKS Model, for counterfactual reasoning

12 For more extensive discussions about the differences between the EKS Model and coherentist approaches, see Khalifa (2016, 2017, Ch. 4). 
appears to be essential for showing how an explanans makes a difference to its explanandum. Since these views also place no constraints on how that explanation is acquired, while the EKS Model specifies SEEing as the preferred pathway to explanatory knowledge, it is also more demanding than these views. ${ }^{13}$

Wilkenfeld's (2013) view requires understanders to be able to manipulate representations in a manner that enables them to perform a context-relevant task. While the EKS Model is not couched in the language of representationmanipulation, the counterfactual reasoning just discussed would seem to qualify as an instance on Wilkenfeld's standards. So, the question is whether fulfilling a context-specific task makes Wilkenfeld's view more or less demanding than the EKS Model. Once again, the preferred vocabularies of the views do not readily line up, but I think that the following is fair. According to the EKS Model, one contextinvariant task is that of having SEEn oneself to a correct answer to a why-question. Wilkenfeld does not even require that one answer a why-question. Thus, the EKS Model is more demanding than Wilkenfeld's account.

Like Wilkenfeld, De Regt (2017) leaves ample room for context-sensitivity, but like the EKS Model, de Regt takes all understanding to require a correct explanation. Rather than focusing on tasks, de Regt focusing on which skills the scientists have for using the available theoretical resources. It's somewhat unclear where the EKS Model and de Regt's approach diverge. ${ }^{14}$ However, for the purposes

${ }^{13}$ For more detailed critiques of these positions, see Khalifa (2017, Ch. 3)

${ }^{14}$ For further discussion, see Khalifa (2017, Ch. 2 and Ch. 6), Khalifa and Gadomski (2013). 
of the present paper, the EKS Model is to be preferred for providing a more precise account of the relationship between warrant and understanding.

Finally, let's examine Newman's $(2012,2013)$ inferential model of understanding. On this view, understanding requires: (1) knowledge that $q$ explains why $p$, plus (2) an ability to provide further inferentially articulated knowledge of the causal, logical, or probabilistic reasons about how $q$ explains why $p$. On the one hand, Newman's view does not require understanding to involve SEEing. So, in this regard, the EKS Model is more demanding than the inferential model. On the other hand, Newman's account of understanding may appear more demanding in requiring inferential knowledge betwixt explanans and explanandum.

This is somewhat complicated. The EKS Model claims that understanding improves in proportion to the amount explanatory information grasped. The inferential model's two conditions might then reflect two different but related pieces of explanatory information: (1) the information required to answer why $p$ ? and (2) the information required to answer how does $q$ explain (cause, etc.) $p$ ? Importantly, the EKS Model claims that it is possible to understand why $p$ via an explanation $q$ without knowing how $q$ brings $p$ about. Newman's view does not tolerate this possibility. So, in this regard, Newman's view is more demanding than the EKS Model. However, the EKS Model does claim that a person who grasped both (1) and (2) would understand why $p$ better than a person who only grasped (1). 
Furthermore, it's unclear that this particular difference between our views has much of a bearing on the Verstehen wars. ${ }^{15}$

Thus, all told, the EKS Model appears more demanding than the other accounts of scientific understanding that have been proposed in the last decade or so. As a result, even if interpretivists can effectively argue that Verstehen does not conform to the EKS Model, there are half a dozen other accounts of scientific understanding with laxer requirements that it must also resist in order to pass the Distinction Test. Once again, we see that interpretivists face substantial burdens of proof once they engage with this new literature on understanding.

\section{Conclusion}

I have argued that philosophers of social science can profit by engaging with recent literature in epistemology and the philosophy of science on the topic of understanding. Using examples from different social sciences, I have argued that my own contributions to the latter literature-primarily in the form of the EKS Model—can be extended to the social sciences. This has implications for the Verstehen Wars, and, in particular, favors the idea that Verstehen is a species of scientific understanding. Furthermore, I have considered some possible interpretivist rebuttals to this claim, and rehearsed some of the hurdles that such rebuttals face.

However, the preceding is more in the spirit of an invitation to carry on a new conversation than it is a shot across the interpretivist bow. I welcome

${ }^{15}$ For further comparison between my view and Newman's, see Khalifa (2015). 
interpretivists to discharge some of the burdens of proof I have presented.

Additionally, I have been silent as to whether the EKS Model imposes sufficient conditions on Verstehen. I conclude by briefly pointing to two issues on this front that deserve further discussion going forward.

First, the EKS Model is highly attuned to the differences between sciences. Different explanations will have different local constraints. Different explanatory evaluations will require different methods and different kinds of evidence. All of these differences occur between different natural sciences just as much as they occur between the natural sciences and the human sciences. So, for interpretivists seeking to establish that Verstehen requires more than scientific understanding, a key question will be whether this "something extra" isn't just a variation on one of these themes.

Second, no two scientific fields are identical, so there will always be differences. Presumably, interpretivists intend for the differences between Verstehen and scientific understanding to be deeper than the differences between, say, understanding in physics and chemistry. But then when do these differences become "deep enough" for interpretivists to declare victory in the Verstehen Wars? ${ }^{16}$ I suspect that this might be the key to settling the Verstehen Wars once and for all.

Baumberger, Christoph, Claus Beisbart, and Georg Brun. 2016. "What is understanding? An overview of recent debates in epistemology and philosophy of science." In Explaining understanding: New perspectives from

${ }^{16}$ For an interesting recent proposal on this front, see Grimm (2017). 
epistemology and philosophy of science, edited by Stephen R. Grimm,

Christoph Baumberger and Sabine Ammon, 1-34. New York: Routledge.

Baumberger, Christoph, and Georg Brun. 2017. "Dimensions of Objectual

Understanding." In Explaining Understanding: New Perspectives from

Epistemology and Philosophy of Science, edited by Stephen Grimm Christoph

Baumberger and Sabine Ammon, 165-189. Routledge.

Carter, J. Adam, and Emma C. Gordon. 2014. "Objectual understanding and the value problem." American philosophical quarterly 51 (1):1-13.

Cupples, Laura. ms. "Measure development and the hermeneutic task."

De Regt, Henk W. 2017. Understanding scientific understanding. New York: Oxford University Press.

Dellsén, Finnur. "Beyond Explanation: Understanding as Dependency Modeling." British Journal for the Philosophy of Science.

Elgin, Catherine Z. 2017. True enough. Cambridge, MA: MIT Press.

Greco, John. 2013. "Episteme: knowledge and understanding." In Virtues and their vices, edited by Kevin Timpe and Craig A. Boyd, 285-301. Oxford: Oxford University Press.

Grimm, Stephen R. 2014. "Understanding as knowledge of causes." In Virtue epistemology naturalized, edited by Abrol Fairweather, 329-345. Dordecht: Springer International Publishing.

Grimm, Stephen R. 2017. "Why Study History? On Its Epistemic Benefits and Its Relation to the Sciences." Philosophy 92 (3):399-420. doi: 10.1017/S003181911700002X.

Hills, Alison. 2015. "Understanding why." Noûs 49 (2):661-688. doi: $10.1111 /$ nous.12092.

Kelp, Christoph. 2015. "Understanding phenomena." Synthese 192 (12):3799-3816. doi: 10.1007/s11229-014-0616-x.

Khalifa, Kareem. 2015. "EMU defended: reply to Newman (2014)." European Journal for Philosophy of Science 5 (3):377-385. doi: 10.1007/s13194-0150112-2.

Khalifa, Kareem. 2016. "Must understanding be coherent?" In Explaining Understanding: New Perspectives from Epistemology and Philosophy of Science, edited by Stephen R. Grimm, Christoph Baumberger and Sabine Ammon, 139-164. London: Routledge.

Khalifa, Kareem. 2017. Understanding, explanation, and scientific knowledge. Cambridge: Cambridge University Press.

Khalifa, Kareem, Gabriel Doble, and Jared Millson. forthcoming. "Counterfactuals and explanatory pluralism." British Journal for the Philosophy of Science.

Khalifa, Kareem, and Michael C. Gadomski. 2013. "Understanding as explanatory knowledge: the case of Bjorken scaling." Studies in History and Philosophy of Science Part A 44 (3):384-392. doi: 10.1016/j.shpsa.2013.07.001.

Kirshner, Robert P. 1994. "The Earth's Elements." Scientific American 271 (4):5865. 
Kvanvig, Jonathan L. 2003. The value of knowledge and the pursuit of understanding. Cambridge: Cambridge University Press.

Mitchell, Sandra D. 1997. "Pragmatic laws." Philosophy of science 64:468-479.

Newman, Mark. 2012. "An inferential model of scientific understanding." International studies in the philosophy of science 26 (1):1-26. doi: 10.1080/02698595.2012.653118.

Newman, Mark. 2013. "Refining the inferential model of scientific understanding." International studies in the philosophy of science 27 (2):173-197. doi: 10.1080/02698595.2013.813253.

Pritchard, Duncan. 2005. Epistemic luck. Oxford: Oxford University Press.

Pritchard, Duncan. 2010. "Knowledge and understanding." In The nature and value of knowledge: three investigations, edited by D. Pritchard, A. Millar and A. Haddock, 3-90. Oxford: Oxford University Press.

Pritchard, Duncan. 2014. "Knowledge and understanding." In Virtue epistemology naturalized, edited by Abrol Fairweather, 315-327. Dordrecht: Springer International Publishing.

Reutlinger, Alexander, and Juha Saatsi, eds. 2018. Explanation beyond causation : philosophical perspectives on non-causal explanations. Oxford, United Kingdom: Oxford University Press.

Riggs, Wayne. 2009. "Understanding, knowledge, and the meno requirement." In Epistemic value, edited by Adrian Haddock, Alan Millar and Duncan Pritchard, 331-338. Oxford: Oxford University Press.

Rosaldo, Renato. 1980. Ilongot headhunting, 1883-1974: a study in society and history. Stanford, CA: Stanford University Press.

Roth, Paul A. 2003. "Beyond understanding: The career of the concept of understanding in the human sciences." In The Blackwell Guide to the Philosophy of the Social Sciences, edited by Stephen Turner and Paul A. Roth, 313-333. Blacwell, Oxford.

Roush, Sherrilyn. 2007. Tracking truth : knowledge, evidence, and science. Oxford: Clarendon.

Ryan, Allison M, Margaret H Gheen, and Carol Midgley. 1998. "Why do some students avoid asking for help? An examination of the interplay among students' academic efficacy, teachers' social-emotional role, and the classroom goal structure." Journal of educational psychology 90 (3):528-535.

Schrödinger, E. 1954. Nature and the Greeks. Cambridge: Cambridge University Press.

Stueber, Karsten R. 2006. Rediscovering empathy: agency, folk psychology, and the human sciences. Cambridge, Mass.: MIT Press.

van Fraassen, Bas C. 1980. The scientific image. New York: Clarendon Press.

van Fraassen, Bas C. 2008. Scientific representation: paradoxes of perspective. Oxford: Oxford University Press.

Wilkenfeld, Daniel A. 2013. "Understanding as representation manipulability." Synthese 190 (6):997-1016. doi: 10.1007/s11229-011-0055-x. 
Woodward, James. 2001. "Law and Explanation in Biology: Invariance Is the Kind of Stability That Matters." Philosophy of Science 68 (1):1-20. doi: $10.1086 / 392863$.

Woodward, James. 2003. Making things happen: a theory of causal explanation. New York: Oxford University Press.

Wylie, Alison. 1999. "Rethinking unity as a 'working hypothesis' for philosophy of science: How archaeologists exploit the disunities of science." Perspectives on Science 7 (3):293-317.

\section{Author Biography}

Kareem Khalifa is currently a professor of philosophy at Middlebury College. His primary research interest is in general philosophy of science, philosophy of social science, and epistemology, with special focus on the topics of understanding, explanation, inference, and epistemic value. He is author of Understanding, Explanation, and Scientific Knowledge (Cambridge, 2017), and of articles in journals such as Australasian Journal of Philosophy, The British Journal for the Philosophy of Science, Philosophy of Science, and Synthese. 